\title{
CONSIDERATIONS ON REDUCTION OF INDOOR AIR POLLUTION FROM RADIOACTIVE EMISSIONS FROM BUILDING MATERIALS AND THE GROUND
}

\author{
ROSARIA IPPOLITO, LUIGI LEPORE \& ROMOLO REMETTI \\ Department of Basic and Applied Sciences for Engineering, 'Sapienza' University of Rome, Italy
}

\begin{abstract}
The goal of this paper is to study the reduction of health risks from indoor radioactive pollutants, as thoron emissions from common building materials, and radon emission from both building materials and the ground. In particular, when dealing with the indoor environment, one of the most important hazard is represented by radon gas, considered by the World Health Organization (WHO) as the second largest cause of lung cancer, cigarette smoke being the first. Such a radioactive gas belongs to the natural radioactive background of radiation, and its presence all over the world is unavoidable.

Radon gas density varies due to microclimatic factors such as temperature, air pressure, humidity and changes in ground layers. Radon gas emerges from the ground and penetrates building basements, accumulating itself into the indoor air, and being breathed in by people. Taking care of the airtightness of windows allows the radon concentration to build up, in some cases beyond reference levels, together with other chemical pollutants, i.e. combustion residues and solvents. The EU Basic Safety Standards, stated in the Council Directive 2013/59/Euratom, based on the last recommendations from the International Commission on Radiological Protection (ICRP) and from WHO, are focusing on risks related to radon gas concentration inside dwellings and working places. On considering that Council Directive 2013/59 Euratom has to be transposed into law by each EU Member State by February 2018, it is recommended that radon issues have to be considered during the design phase of the building construction. For NZEB applications a special attention is requested when energy consumption is reduced lower and lower by taking care of airtightness. In such a case, indoor pollutants (chemical, radioactive, particulate, etc.) can significantly accumulate beyond safe levels.

This paper describes measurements and remedial actions of study cases, focusing on public and domestic environments.
\end{abstract}

Keywords: indoor air pollution, radon, aerosols, remedial actions.

\section{INTRODUCTION}

Nowadays, the energy-and-costs saving culture is propagating over and over. In the last decade, the buildings industry has been affected also, and new construction trends have been developed: e.g. solar panels, wind generators, shadowing systems, thermal insulation materials, energy-losses control, etc. All those strategies to minimize the building consumptions in energy.

In such a contest, the aspect of the indoor air quality assumes particular interest. Current trends tend to care about windows and doors' sealing, rendering the internal environment an air-tight system. In such a way, if a periodical air renewal (natural or artificial) is not present, internal air pollutants may build-up to concentrations-in-air that could be reason of concern to people's health.

Alongside chemical pollutants (e.g. combustion residues from kitchen fires or fireplaces, solvents from paints and finishing, etc.), radon gas plays the role of radioactive pollutant, being a noble gas that emerges from the ground and/or building materials, easily diffusing in structures and accumulating in closed environments. According to the World Health Organization (WHO) radon is the second largest cause of lung cancer to the general population, cigarette smoke being the first one. Epidemiological studies have provided 
evidence of an association between indoor radon exposure and lung cancer, even at the relatively low concentration levels commonly found in residential buildings [1]. The International Commission on Radiological Protection (ICRP) revised the risk assessment about radon in [2], confirming WHO concerns about residential exposure for the public in domestic environment. Such considerations were merged in the EU 2013/59 Euratom Council Directive, that introduced new recommendations to be transposed into law by each EU Member State by February 2018. From [3], the reference level for radon indoor concentration, including both working and residential, shall be set to $300 \mathrm{~Bq} / \mathrm{m}^{3}$ at maximum.

The attention given to radon issues into this paper lies on interesting reasons of concern: 1) radon production in ground, and dynamic behaviour from the environment to dwellings are strongly related to local peculiarities (soil origin and constitution, microclimate conditions [4]) and building materials used; 2) radon benefits of air draught by windows, and a very small air-exchange with the external environment, typical of the old-fashioned wooden windows, could mitigate significantly radon build-up at indoor locations [5]; 3) radon buildup at indoor location, being the radon concentration a measurable quantity vs time, could be interpreted as an overall air-quality indicator, providing an 'alarm signal' to manage an airventing system to heal the dwelling conditions.

At the Department of Basic and Applied Sciences for Engineering in Sapienza, University of Rome, the Laboratory for Radiation Protection is endowed with the most updated instrumentation and calculation tools for managing all radon exposures. In this paper, two real case scenarios are presented: 1) scattered measurements across a ten-year term monitoring radon into a working place, showing the extreme variability of radon concentration-in-air in the long-term; 2) a monitoring campaign into a residential dwelling, evaluating and showing the effects of some remedial actions artificially introduced on radon build-up.

The work herein presented is intended to underline how periodical or continuous radon monitoring at indoor locations (by active instrumentation) could be worth undertaking to acquire precious information about air quality to people's health, as well as to containing energy losses and mechanical venting system consumptions by realizing an air-renewal when truly needed.

\section{CASE STUDY \#1: A WORKING PLACE IN A BASEMENT}

At the Department of Basic and Applied Sciences for Engineering in Sapienza, University of Rome, the Laboratory for Radiation Protection takes care of all radon issues in the area from 2000 on. The active monitor AlphaGuard [6] provides radon concentration-in-air values hourly, allowing the reconstruction of radon evolution vs time. It is a portable equipment designed for instantaneous or continuous measurement of radon gas in the environment, mines, laboratories and also for complementary investigations in buildings. Air, water, soil, emission measurements are performed thanks to a large range of accessories and external probes. Employing a high-efficiency ionization chamber for measuring $\alpha$ particles in air and discriminating different energies, it is particularly suitable for the verification of requirements, due to its performances and enhanced sensitivity if compared to the other detectors' techniques. Moreover, it is provided with microclimatic sensors to register temperature, air pressure and relative humidity in time, allowing to estimate empirical correlations with the radon concentration.

The attention given to radon issues in the area of the Department is gathering on the fact that the subsoil underneath hosts the S. Hippolytus Catacomb, one of the biggest in Rome. Currently, the Catacomb is closed due to bombardment damages in WWII. Being dug in tuff mainly, its widespread web of tunnels on five levels causes a large radon-reservoir; 
differential pressures and pathways to the ground with low hydraulic resistance allow radon to be drained; dwellings on such pathways undergo significant radon build-up [7].

On considering such a peculiarity, periodical screening campaigns in dwelling and building of the Department have been carried out during the years. The main result, alongside the determination of some dwelling 'reason-of-concern', is the discovering of a dynamic fluctuation about radon build-up in a single place. i.e. a room above the reference level at a certain time, in the following monitoring actions may be confirmed as radon-risky or not, and vice versa.

Such fluctuation behaviour about radon build-up leads to the following consideration: 1) suppose that a room with radon above the reference level is found; 2) the room usage could be changed to limit personnel presence and exposure to radon, e.g. an office being transformed into a storage room; 3 ) if personnel presence cannot be avoided, the room is provided with a mitigation action (e.g. a mechanical suction system to intercept the radon pathway to the room and discharge radon stream in atmosphere by a chimney); 4) random changes in radon pathways from subsoil to the surface could happen, making the room previously considered no more risky, moving the 'radon-issue' to the next room; 5) actions $\# 2$ and \#3 should be repeated to limit radon exposure in such a new scenario.

The hypothesis previously presented could be redone in a specular way, i.e. a radon-risk free room in the current monitoring campaign that turns out to be a reason of concern in the next monitoring action, requesting the application of the countermeasures $\# 2$ and $\# 3$ in the previous list.

The fluctuation of radon build-up here outlined should request special considerations and a specific procedure to care about workers and public's health. The real case scenario here shown could be with no doubt generalized to the whole city of Rome, being the subsoil heterogeneous in composition and historical stratifications.

Fig. 1 shows the radon concentration-in-air at the Laboratory for Radiation Protection (Department of Basic and Applied Sciences for Engineering in Sapienza), being the AlphaGuard monitoring system kept powered and recording twenty-four hours a day. The lack of data in short-term can be addressed to measurements in other sites, while the longterm lack from 2007 to 2012 is due to the loss of the electronic database on an old PC. Being the Laboratory not provided with a remedial action in the current situation, when personnel enter the Laboratory, they are committed to read the radon concentration value on the AlphaGuard display, and open the windows if needed. In few minutes, the radon concentration falls to safe levels.

The advantage of the active measurement in time is evident. A continuous radon monitoring by means of an active detection system:

i) gives a quick response (from few minutes to one hour, to obtain good statistics) easy to be read from each member of the public;

ii) follows radon evolution vs time (24 measured values per day, at least);

iii) enables mitigation system (e.g. windows opening by an operator or HVAC ventilation) to drain out radon from the location in which an excessive concentration has been measured, when truly needed.

In the light of the recent Regulatory developments about the attention the radon monitoring deserves, it seems that active instrumentation systems for concentration-in-air assessment could get a privileged role if compared to passive methods (e.g. CR39 sheets [8]), when performing the verification of requirements for radon build-up at indoor locations. 


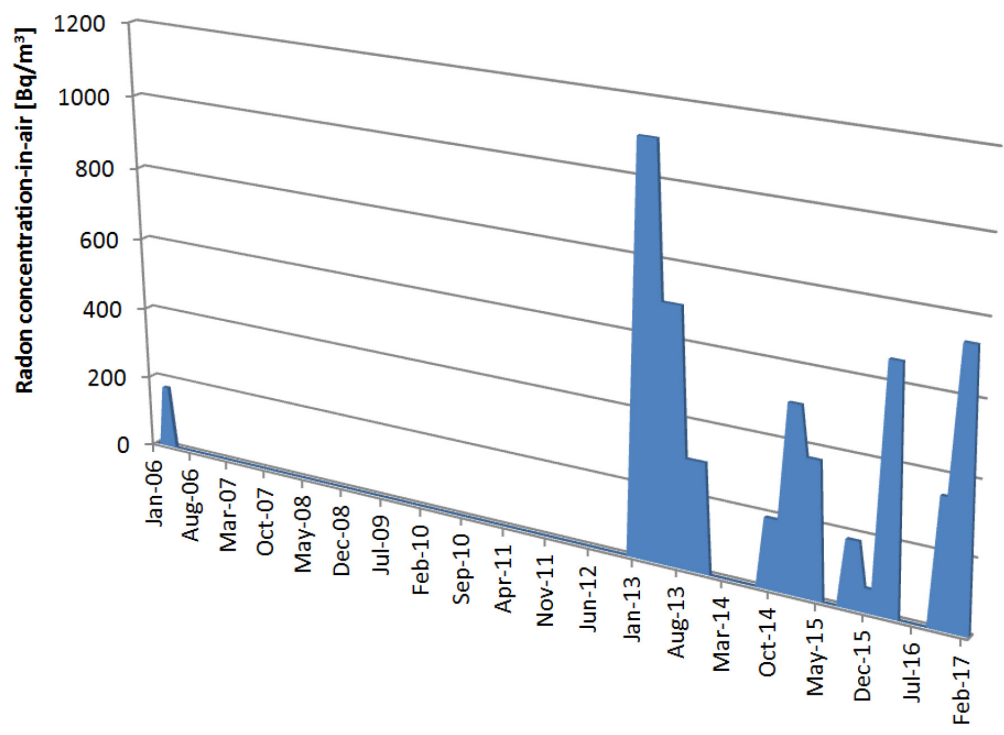

Figure 1: Scattered radon concentration-in-air measurements at the Laboratory for Radiation Protection (Department of Basic and Applied Sciences for Engineering in Sapienza) across a ten-year term with the active monitor AlphaGuard [6]. Each vertical bar is representative of a 3-month average value. As can be seen, significant fluctuations happen, ranging from measurements highly above the reference level $\left(1100 \mathrm{~Bq} / \mathrm{m}^{3}\right.$, in the maximum point, 'Feb-13') to safer values $\left(70 \mathrm{~Bq} / \mathrm{m}^{3}\right.$, in the minimum point, 'Dec-15'), with no significant changes in room usage.

The specific issue about radon air-pollution-variability in long-term here shown reinforces such a concept, envisaging a significant development for radon active instrumentation, to monitor the air-quality situation in real time, initiating some remedial actions to heal the indoor conditions when needed.

\section{CASE STUDY \#2: A RESIDENTIAL DWELLING IN A BASEMENT}

A residential building in Ciampino (RM) has been considered to study the effects of some remedial actions vs radon build-up in a dwelling space. This building, built in 1925 in typical Liberty architecture, is made of bricks, and its foundations rest on a lava stone bench.

The peculiarity of the house here considered lies on an underground cellar for wine storage dug in peperino, a typical magmatic rock. Belonging the municipality of Ciampino to the Colli Albani Volcano area, the territory is characterized by a significant radon emanation due to the high content in uranium and thorium-nuclide-series in ground materials. Moreover, buildings in the area take advantages of local subsoil materials (being dug from foundations during their construction). Because of those facts, a significant radon issue in the building analyzed is expected.

Measures carried out herein are showing a confirmation of such expectation.

Fig. 2 shows the building main facade, while Fig. 3 reports the dwelling configuration in the basement and the position of the remedial actions introduced to manage the radon issue. 

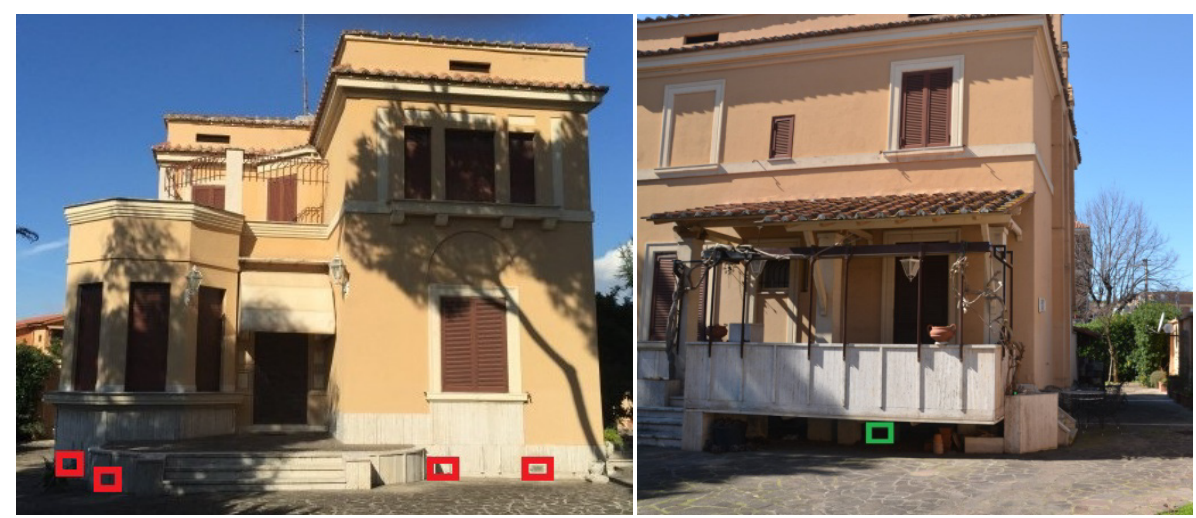

Figure 2: Left: the residential building main facade; windows for the basement ventilation are highlighted in red boxes. Right: building eastern facade; the venting hole from the cellar is highlighted in the green box.

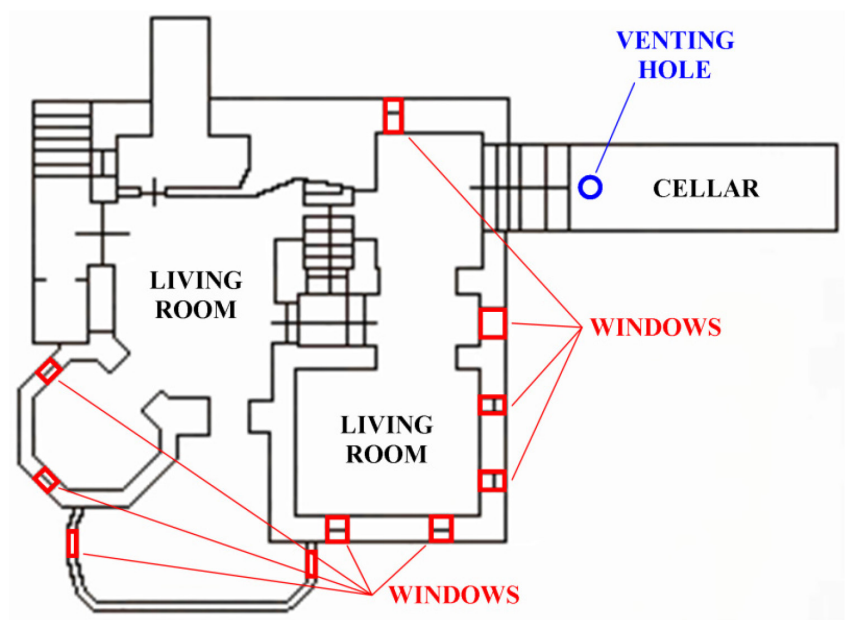

Figure 3: Planimetry of the residential dwelling in Ciampino (RM). The cellar, dug in peperino, is connected to the living room via a wrought-iron and glass door. In blue, the remedial action 'venting hole' is depicted; in red, the remedial action 'windows opening' is shown.

The monitoring campaign is divided in two main groups: 1) radon measurements in the cellar vs remedial actions; 2) radon measurements in the living room vs remedial actions. Such remedial actions can be synterized in:

- a 'venting hole' in the cellar ceiling, Fig. 4;

- a 'windows opening' in the living room.

Each action can be switched in status ON, when communication with the external environment is allowed and radon can be diluted, or OFF when communication with the external environment is avoided. The combination among the two action-states causes 4 different measurement set, as resumed in Fig. 5. 

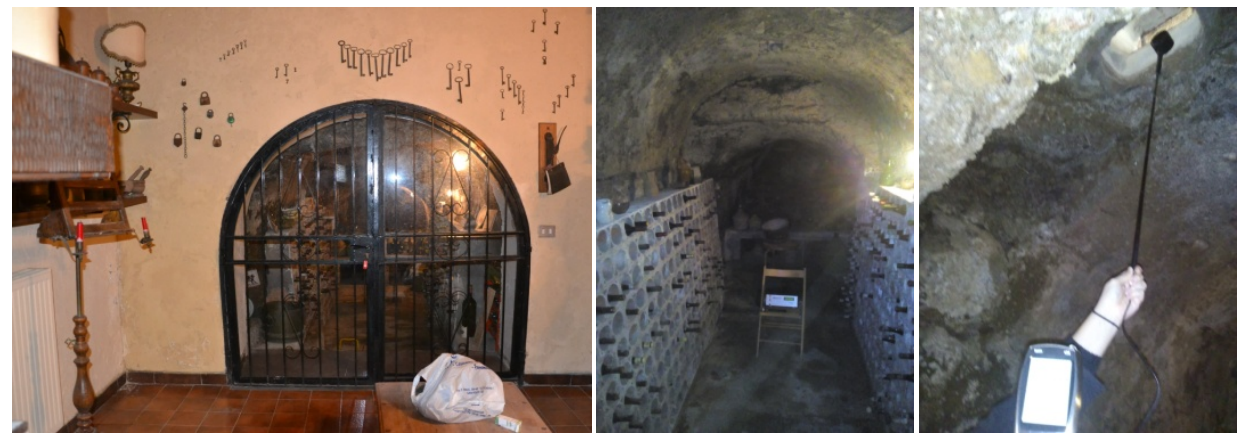

Figure 4: Some photos of the cellar in the basement. Left: the wrought-iron door communicating with the living room. Centre: the cellar, dug in peperino and ground (the AlphaGuard is lying on a chair). Right: the venting hole in the cellar ceiling, during an air-flow measurement.

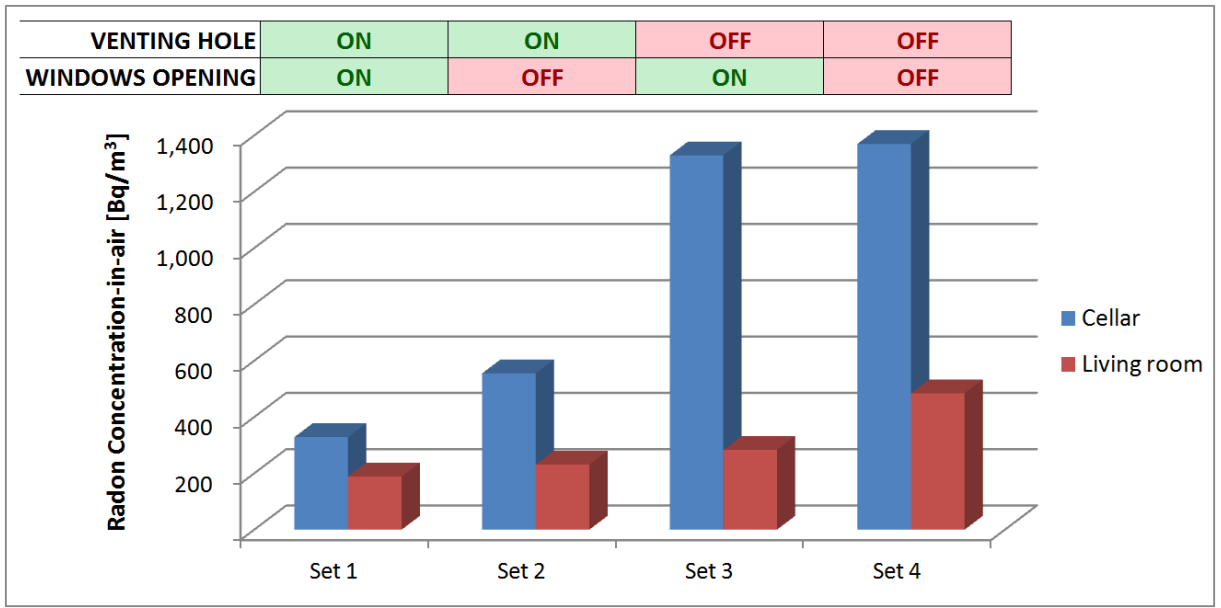

Figure 5: Radon concentration-in-air in dwelling at a residential building in Ciampino (RM) vs remedial actions applications. Each set is representative of a specific configuration of two remedial actions introduced, as specified in the chart over the histogram. Each bar represents a five-day-averaged value in constant conditions (the house is being inhabited) except for the weather. Measures have been carried out in February and March 2017. On considering that the venting hole is in the cellar (being dug in peperino, it is the main source of radon), its closure causes the most significant build-up in that space, while windows opening in the near living room is less important. About the living room, both two remedial actions cause a similar mitigation effect.

Weather, indoor and outdoor temperatures and atmospheric pressure are being monitored and recorded with radon measurements. Air-flows values through the venting hole and windows have been estimated and also $\mathrm{CO}_{2}$ concentration-in-air measured. For the sake of brevity, only significant values will be remarked in the following. 
A radon measurement in each set is calculated as a five-day-averaged value, as to account for weather variation from a day to another, homogenizing the measurements in different sets on microclimatic parameters. It is worth to remark that the building is inhabited, then measurements are not disturbed by people day-life dynamics.

Fig. 5 resumes the results for all the different measurement sets identified. Regarding the 'cellar' measurement group, when actions are being considered individually, the 'venting hole' remedial action is the most significant, reducing radon concentration with a $\sim 62 \%$ efficiency. It is worth to remark that the air-flow measured throughout the venting hole is in the order of $50 \mathrm{~m}^{3} / \mathrm{h}$, corresponding to $\sim 1$ air-change per hour. The 'windows opening' shows a smaller effect on radon mitigation in the cellar ( $3 \%$ efficiency) due to the building layout.

Regarding the 'living room' measurement group, when actions are being considered individually, the two remedial actions cause a similar mitigation effect, with a diluting efficiency from 53 to $44 \%$ for the 'venting hole' and 'windows opening', respectively. The 'venting hole' ON (and 'windows opening' OFF) dilutes the radon in the cellar, reducing the quantity penetrating the living room; the 'windows opening' ON (and 'venting hole' OFF) causes a large radon quantity entering from the cellar to the living room, but concentration is diluted via the air renewal by windows.

With both remedial actions ON, 79\% and 62\% diluting efficiencies are found, for the cellar and the living room respectively.

It is worth to remark indoor ambient parameters influence. Fig. 6 shows temperature, pressure, and relative humidity. Data point out the effects on radon concentrations, highlighting expected trends.

\section{RESULTS AND DISCUSSION}

The study cases here analyzed have shown different peculiarities about radon-issues vs the internal air quality.

From the case study \#1, a dynamic behaviour of radon build-up in a working dwelling is outlined, showing the need in providing a specific treatment of all situations similar to the
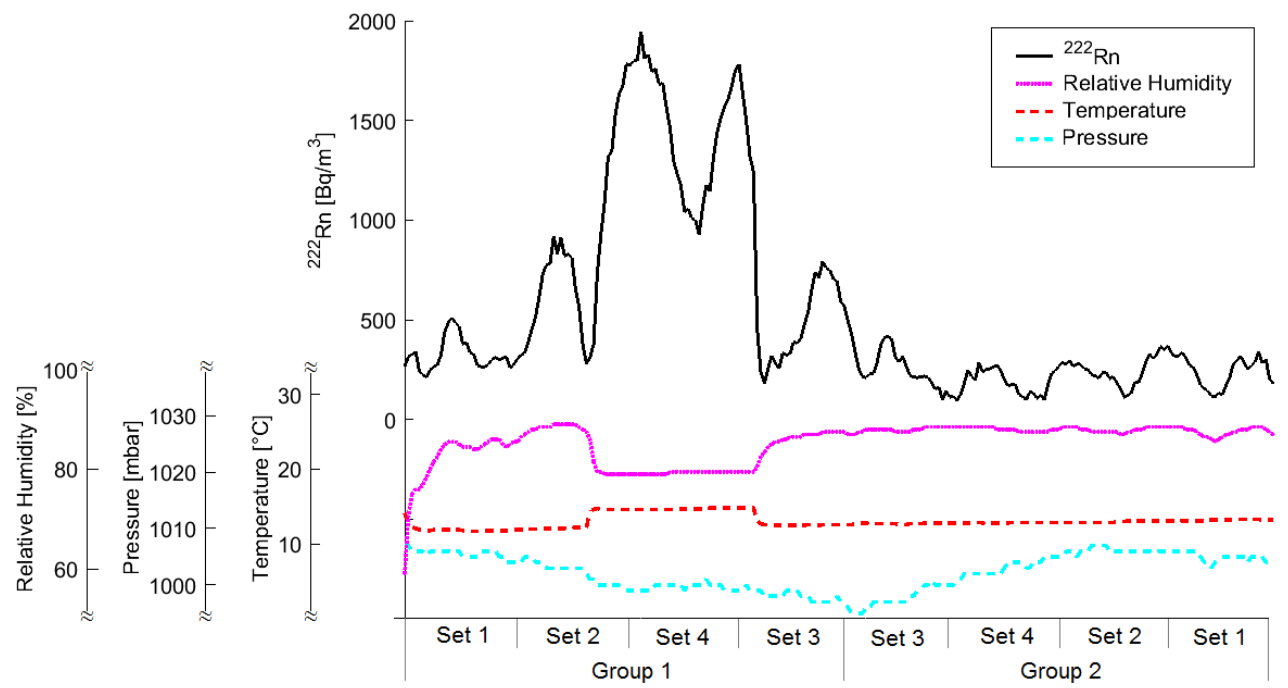

Figure 6: Influence of microclimatic parameters. Dependence of radon concentration in indoor air vs temperature, pressure and relative humidity. 
building here analyzed. Radon reservoirs in the ground can change in time, especially in porous subsoil or particular configuration of the ground underneath the building, such as happen to the city of Rome. A dynamic radon monitoring, alongside a dynamic activation of the remedial action suggest to be the best solution to face the radon-risk, and limit the building energy consumption.

From the case study \#2, some remedial actions have been evaluated and efficiencies calculated in four different sets. Even if each building has its own peculiarities, a general consideration can be resumed: simple remedial actions, such as windows opening or a venting channel allowing air natural circulation, mitigate radon build-up at the indoor location significantly, increasing the internal air quality by diluting all pollutants. However, a constant remedial action (a window constantly open or a ventilation fan ever powered), could turn out to be excessive while not accounting for the natural dynamic variations of radon emanations from ground and building materials, and the day-life dynamic of the location (radon buildup in the day is mitigated intrinsically by anthropic activity, due to doors and windows opening). As a result, even in this case, a dynamic radon monitoring, alongside a dynamic activation of the remedial action should be elected as the best solution.

A resume of the work here carried out is depicted in a flowchart in Fig. 7.

As a result of the dynamic behaviour of radon build-up at indoor locations here shown, further considerations could be made as suggestion to manage the radon-risk and the internal air quality. On considering an existing building or a structure under construction in a territory when radon-issues are known to be faced, the specific expert appointed with the remedialaction design should care about the dynamic fluctuation here outlined and plan a radon mitigation action in the most flexible way. The best technical solution should have installed all at once, with minimal corrections to follow the fluctuations.

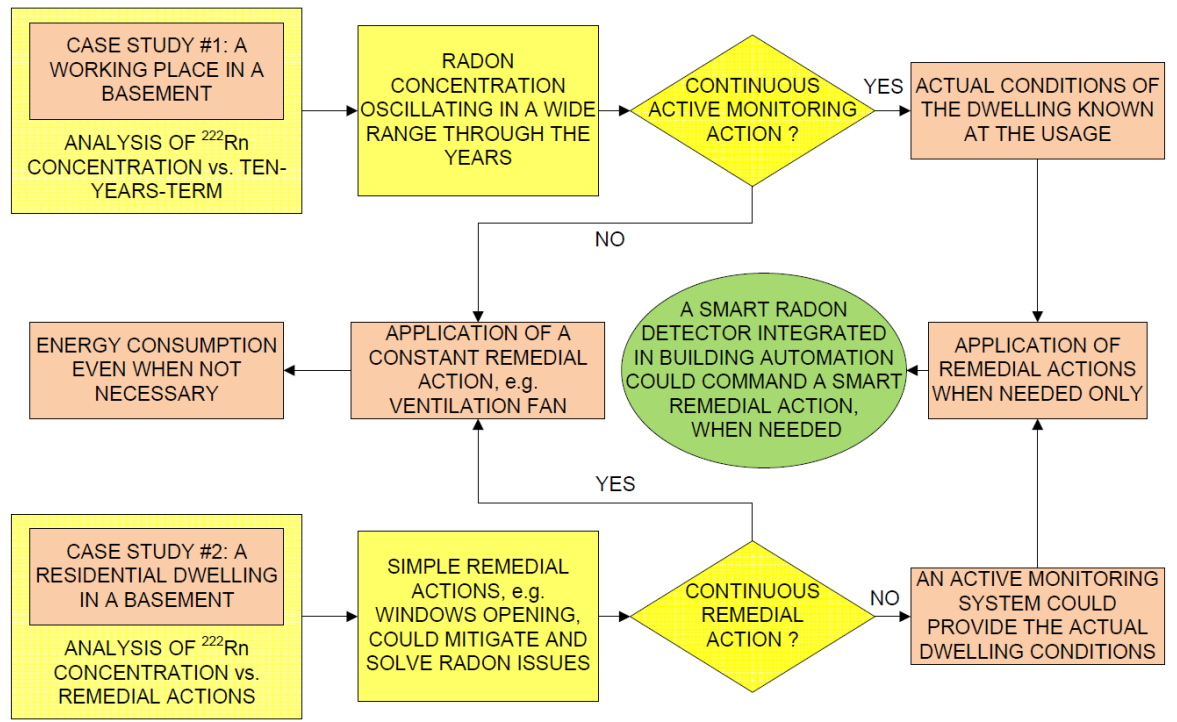

Figure 7: Flowchart of the work here shown. Both two study cases here analyzed could benefit from a smart monitoring and mitigation action about radon air-pollution. An active detector could measure the current condition and air quality at the indoor location, initiating a healing action (e.g. mechanical ventilation) to reduce the internal air pollution. 


\section{CONCLUSIONS}

The paper aimed to show some peculiarities about the radon-related risk to people health at indoor locations, when poor air-renewal could cause a significant build-up of radon and other pollutants (e.g. chemicals, combustion residues, etc.), with an overall reduction of the 'quality' of the air being breathed by people.

Radon gas is emanated from ground and building materials according to the uranium and thorium-nuclide-series contents: these contributions are the main part of the Earth crust natural background of radiation. According to WHO, radon is the second largest cause of lung cancer, cigarette smoke being the first one.

Current trends in taking care of windows' airtightness to reduce the building energy consumptions enhance the radon-issue, allowing its concentration to build up, in some cases beyond reference levels. The EU Basic Safety Standards, stated in the Council Directive 2013/59/Euratom (being transposed into law by each EU Member State by February 2018), increases the attention to radon-issues at indoor locations by reducing the reference levels, and envisaging remedial actions for existing buildings and recommendation in considering radon mitigation action from the building design phase for new constructions.

The goal of this paper was to study the dynamic fluctuation of radon build-up in longterm at indoor locations (radon gas density varies due to microclimatic factors such as temperature, air pressure, humidity and changes in ground layers), alongside the evaluation of the efficiency of some remedial actions introduced to mitigate the radon accumulation-inair. Real measurements in two study cases were presented, employing the active monitoring system AlphaGuard as a screening survey tool. Its microclimatic parameters' recording, alongside radon concentration measurement, suggested how to intervene on the case study analyzed to those not-expert in radiation measurement too, by evaluating the best practice to introduce as remedial action. Countermeasures against radon build-up in the study cases here analyzed have been set, as to meet the verification of requirements of the Council Directive 2013/59/Euratom [3] to people's health.

As a main result, radon build-up could be managed throughout simple remedial actions (e.g. air renewal by a window opening or a mechanical ventilation), with little cost and high efficiency if the remedial action introduced is being appropriate to the case analyzed. Today, common trends in remedial action applications envisage the application of a constant mitigation action, without considering the dynamic fluctuations of radon build-up.

The best solution seems to be in a smart radon sensor, capable in detecting the indoor airquality and commanding the start-up of a mitigation action only when truly needed. Then, the remedial-action design should care about the dynamic fluctuation here outlined, being flexible (with minimal corrections) to 'follow' the radon build-up and fluctuations in the building.

At the Department of Basic and Applied Sciences for Engineering in Sapienza, University of Rome, the Laboratory for Radiation Protection is studying some active detectors to monitor radon concentration-in-air, as to evaluate their real applicability at indoor scenarios, as depicted before. Alongside such evaluation, a new detector is under development, envisaging the possibility to conceive an innovative radon detector, cheap and reliable to meet the goals sketched in this study.

\section{REFERENCES}

[1] World Health Organization, WHO Handbook on Indoor Radon: A Public Health Perspective. Geneva, 2009. 
[2] Tirmarche, M., Harrison, J.D., Laurier, D., Paquet, F., Blanchardon, E. \& Marsh, J.W., Lung Cancer Risk from Radon and Progeny and Statement on Radon, ICRP Publication 115, Ann. ICRP, 40(1), 2010.

[3] EU Council, Council Directive 2013/59/Euratom. Available from: http:/eurlex.europa.eu/legal-content/IT/TXT/?uri=CELEX\%3A32013L0059, 2014.

[4] Ippolito, R. \& Remetti, R., Studio sperimentale dell'influenza di parametri microclimatici sulle concentrazioni di gas radon in ambiente confinato. Sviluppo sostenibile, tutela dell'ambiente e salute umana (ISBN:9788860740182), 2006, pp. 171176.

[5] Remetti, R. \& Gigante, G.E., Experimental study on the influence of natural and artificial ventilation on indoor radon concentration. Giornale Italiano di Medicina del Lavoro ed Ergonomia, 32(4 suppl. 1), 2010, pp. 245-247.

[6] Saphymo, Environmental Radiation Monitoring System: AlphaGuard. Available from: www.saphymo.com/radiation-measurement/environmental-radiation-monitoringsystems/alphaguard/154.htm.

[7] Remetti, R., Remarks on the variability of radon indoor concentrations in Italy. Journal of Materials Science and Engineering A 1, (formerly part of Journal of Materials Science and Engineering), 2011, pp. 838-843.

[8] Ippolito, R., Characterization of passive nuclear tracks detectors for measurement of indoor radon. Available from: www.isprambiente.gov.it/contentfiles/00001100/1158rosaria-ippolito.zip/view, 2004. 